\title{
Efficacy of an extended-release tilmicosin preparation and tulathromycin in the treatment of bovine respiratory disease
}

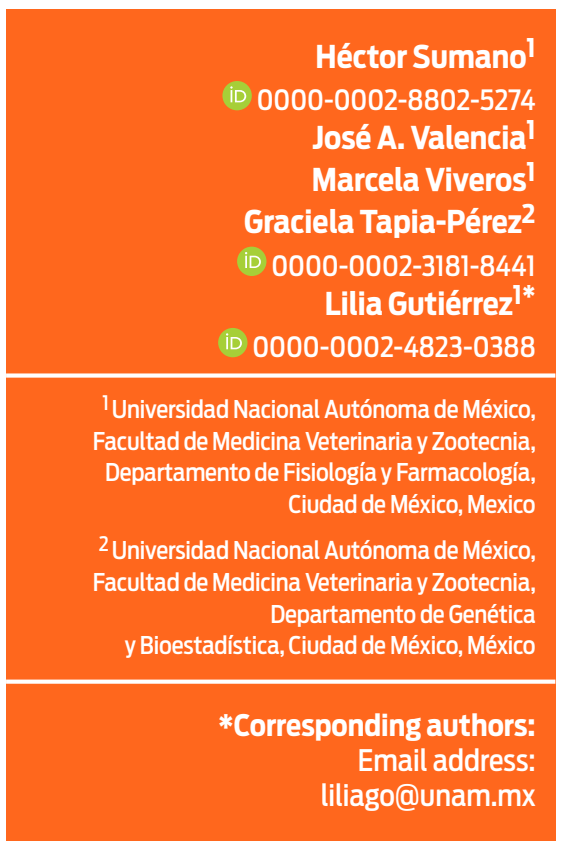

Published: $\quad 2020-12-18$

@) Copyright 2020 Héctor Sumano et al.

\begin{abstract}
A trial to evaluate the treatment of bovine respiratory disease (BRD) was established with tulathromycin (Tul-group) and tilmicosin (Til-group). This latter antibacterial drug is pharmaceutically prepared for 8-10 d sustained release. The challenge was carried out with spontaneously BRD-affected bulls, divided into Til-group $(\eta=44)$ and Tul-group $(\eta=50)$. Bulls were treated only once with either antibacterial drugs. Bacteriological analysis, arterial and venous blood chemistry, gasometrical parameters, and body temperature were obtained before and after treatment. The clinical cure rate was registered on days 7, 15, and 30. No mortality was observed. Clinical cure was statistically undistinguishable on these days (P> 0.05), and in both groups, all animals were considered healthy until day 30 . Only customary pathogens were isolated i.e., Mannhemia hemolytica 38.88\% (70/180), Pasteurella multocida 26.11\% (47/180), Histophilus somni 18.33\% (33/180, and Trueperella pyogenes $16.66 \%(30 / 180)$.
\end{abstract}

Keywords: Bovine; Clinical efficacy; Tilmicosin-long acting; TulathromycinIntroduction

\section{Cite this as:}

Sumano H, Valencia JA, Viveros M, Tapia-Pérez G, Gutiérrez L. Efficacy of an extendedrelease tilmicosin preparation and tulathromycin in the treatment of bovine respiratory disease. Veterinaria México OA. 2020;7(4). doi:10.22201/fmvz.24486760e.2020.4.787 


\section{Introduction}

Bovine respiratory disease (BRD) is the main cause of economic losses in commercial beef production because of its impact on mortality, the cost of treatment, and the negative effect on the performance of cattle. In feedlots, the death toll due to BRD can be as high as 50\%, with 75\% morbidity. ${ }^{1}$ Predisposing factors to BRD are often related to stress, such as prolonged transport, exhaustion, starvation, dehydration, climatic variations, changes in diet, neutering, dehorning, overpopulation, and inadequate confinement. ${ }^{2}$ BRD is often linked to pathogens such as Bovine-1 Herpes Virus, Bovine Viral Diarrhea, Parainfluenza 3, and Bovine Respiratory Syncytial Viruses. Bacteria involved include Mannheimia haemolytica, Pasteurella multocida, Histophilus somni, and Mycoplasma bovis. ${ }^{3}$ Individual clinical manifestations may vary from one outbreak to the next, even within a group of affected animals. Under field conditions, the diagnosis of BRD is based on the clinical assessment of the individual steer or bull. The main signs of BRD are general depression, anorexia, increased conjunctival secretion, fever $\left(>\right.$ than $40{ }^{\circ} \mathrm{C}$ ), tachycardia, respiratory distress, and sometimes the flank area is depressed as an indication of poor food consumption. Unfortunately, these signs are common to other diseases and certain behavioral responses. The severity of BRD has been graded as follows: 1 (normal, without clinical signs); 2 (with slight variation from normal); 3 (abnormal), and 4 (severely abnormal) for temperature, nasal discharge, cough, ocular discharge, and the position of the ears. ${ }^{4}$ Additionally, it has been described that severities of individual cases have low correspondence with how clinical signs are manifested. ${ }^{5}$ This explains why this diagnostic methodology has limited sensitivity to detect BRD, with $55.4 \%$ sensitivity and 58\% specificity. ${ }^{6,7}$ Other methods to increase diagnosis certainty of BRD have been tried with limited success. For example, the identification of specific microbial agents requires too much time and a detailed understanding of the pathogenesis associated with each bacterial or viral disease, as well as selecting the appropriate biological samples and processing them correctly. ${ }^{8-10}$ Quantification of serum cortisol concentrations has been proposed as a measurement of stress caused by BRD, and this approach offers $53.8 \%$ specificity and $100 \%$ sensitivity to diagnose BRD. ${ }^{11}$ When salivary cortisol is quantified, $70 \%$ sensitivity and $52.9 \%$ specificity are obtained to diagnose BRD. ${ }^{11}$ Quantification of acute-phase proteins of inflammation found during BRD, such as haptoglobin and lipopolysaccharide bound to protein, has also been evaluated, achieving 90\% sensitivity and specificity to diagnose BRD. These proteins have been proposed as a confirmatory diagnosis but are not adequate to grade the severity of a given clinical case. ${ }^{12}$ The use of rectal temperature, which was previously the most reliable variable, is now considered to be of low predictive value. ${ }^{13}$ In practical terms, the application of laboratory techniques in fieldwork is somewhat idealistic, not only in terms of cost but also because of management and low access to laboratory facilities. Given the above, it has been suggested that quantification of partial oxygen pressure $\left(\mathrm{PaO}_{2}\right)$ with portable equipment could be a better predictive parameter of BRD. Also, the severity of the pulmonary lesions as damage to the pulmonary parenchyma will decrease the ventilation/perfusion ratio, will induce alveolar and systemic hypoxia and in turn, these changes would allow a more accurate diagnosis of BRD. ${ }^{14}$

Two approaches have been used to deal with BRD: a metaphylactic antibacterial treatment (with tulathromycin) and individual treatments with tilmicosin, as a response to the clinical diagnosis of BRD. Evidence supporting the metaphylaxis 
has shown important cost: benefit ratio advantages, mainly based on the reduction in the number of second treatments, as compared to tilmicosin. ${ }^{15}$ However, as these authors found, production-performance data were not different between treatments throughout the study. Some studies based on metanalysis ${ }^{16,17}$ conclude that fewer treatments after metaphylaxis therapy with tulathromycin are needed, in comparison with other commonly used antibiotics. In contrast, recent studies show that the percentages of calves that required more than one treatment for BRD within $45 \mathrm{~d}$ after arrival did not differ statistically when comparing those receiving enrofloxacin when bulls were diagnosed as affected by BRD, compared with those receiving tulathromycin as metaphylaxis. ${ }^{18}$ In addition, as antimicrobial resistance represents one of the most important human and animal health-threatening issues worldwide, the use of antimicrobial drugs for metaphylaxis has been perceived as contrary to an adequate use of these drugs in animal production. ${ }^{19,20}$ Considering this and based on the fact that the greatest majority of beef producers in Mexico rely on treating only BRD affected bulls, this study was conducted to evaluate the clinical efficacy of two highly effective antibacterial preparations for the treatment of BRD, tulathromycin (Draxxin ${ }^{\circledR}$, Zoetis, México City) ${ }^{21}$ and a new tilmicosin preparation designed for sustained release [manufactured by Casal's Internacional S.A. de C.V. (Guadalajara, Mexico), under Patent MX/E/2014/01 1982 held by the National Autonomous University of Mexico (UNAM), Instituto Nacional de la Protección Industrial (INPI), Mexico City, Mexico]. This tilmicosin preparation achieves 8-10 days of therapeutic plasma concentrations i.e., above $0.1 \mu \mathrm{g} / \mathrm{ml} .^{22,23}$ Thus, the specific setting for this trial was the treatment of bulls diagnosed with BRD, clinically classifying the disease into four degrees of severity. Body temperature was measured, and arterial and venous blood samples were taken to quantify partial pressure of oxygen and $\mathrm{CO}_{2}$ to correlate these values with the clinical classification of BRD. Additionally, the arterial and venous $\mathrm{pH}$ values, the hematocrit, the blood concentrations of $\mathrm{Na}^{+}, \mathrm{K}^{+}, \mathrm{Ca}^{2+}, \mathrm{Cl}^{-}$, lactate, and glucose were also measured.

\section{Materials and methods}

All procedures were approved by the Institutional Committee for Research, Care, and Use of Experimental Animals of the National Autonomous University of Mexico (UNAM), and they were conducted according to Mexican Official Regulations (NOM-062-ZOO-2001). This study was carried out in a commercial feedlot located in the state of Jalisco, Magdalena district, within the State of Jalisco located at $20^{\circ}$ $54^{\prime}$ latitude, $103^{\circ} 59^{\prime}$ longitude and 1,400 $\mathrm{m}$ above sea level, with a semi-dry climate, an average annual temperature of $21.4^{\circ} \mathrm{C}$ and annual rainfall of $1013 \mathrm{~mm}^{3}$. This study was carried out during the period from December 2018 until February 2019. In the feedlot, pens were 70-72 $\mathrm{m}^{2}$, designed for 12 bulls (approximately $6 \mathrm{~m}^{2}$ /animal), with $3 \mathrm{~m}^{2}$ shades per bull and feeders in line considering $60 \mathrm{~cm} /$ bull. In each pen, freshwater was supplied ad libitum through two $6 \mathrm{~m}^{3}$ water basins, $1.2 \mathrm{~m}$ high. 


\section{Animals}

Selected bulls for this study came from different farms in the zone. Upon arrival (day 0), all animals entered a reception protocol established on this feedlot, which includes: immunization, deworming, and steroidal implantation (Revalor, MSD ${ }^{\circledR}$, Mexico City, Mexico). Individual animals were identified by ear tags and their weight and place of origin were recorded. The bulls were housed in communal pens with dirt floor, exercise and shade areas, having food and water ad libitum. Cattle that presented clinical signs of BRD were classified according to Table 1 for severity, and only bulls classified as 2 or 3 were included in this trial (Table 1). Diagnosis and severity grading were carried out by the veterinarian in charge of the herd. In the end, 22 and 18 bulls classified as severity 2 and 3 respectively, were assigned to a group treated with tilmicosin-LA. Similarly, 26 and 19 bulls with the same severities were assigned to a group treated with tulathromycin. Body temperature was obtained using imaging by FLIR ${ }^{\circledR}$ E8 thermal imager (FLIR ${ }^{\circledR}$ Instruments, Italy), with a sensitivity reported by the manufacturer $<0.06{ }^{\circ} \mathrm{C}$. The device light beam was directed towards the eye's conjunctiva as previously recommended. 24,25 Blood samples were taken from the caudal veins and the medial coccygeal artery using Vacutainer tubes with heparin. Blood samples were immediately processed by a portable gasometer (VetStat ${ }^{\circledR}$, INDEXX, Desego, Mexico City, Mexico) and the following variables were obtained: arterial and venous $\mathrm{pH}$, venous and arterial partial pressures of carbon dioxide $\left(\mathrm{pCO}_{2}\right)$ and oxygen $\left(\mathrm{pO}_{2}\right), \mathrm{Na}^{+}, \mathrm{K}^{+}, \mathrm{Ca}^{2+}, \mathrm{Cl}^{-}$, lactate ( $\mathrm{Lac})$, glucose content (Glu) $(\mathrm{mg} / 100 \mathrm{ml})$ and hematocrit $(\mathrm{Ht} \%)$.

\section{Clinical cases}

Clinical cases included in this trial were classified based on a clinically acceptable scale, ${ }^{5}$ which is based on the presence or absence and intensity (mild to moderate) of general depression, lethargy, weakness, reduction in the intestinal filling, lack of attention to the environment, and reduced willingness to move as a response to disturbances. These are common clinical signs easily recognizable by clinicians in the field. Neither animals graded 1 nor 4 on the scale presented in Table 2, nor bulls concurrently exhibiting signs of diarrhea were eligible for this study.

Two groups were set as follows: (1) (22 and 18 bulls classified as severity 2 and 3 respectively; $n=40$ ) treated with tilmicosin-LA (Til), manufactured by Casal's Internacional S.A. de C.V; Guadalajara, Mexico, under Patent MX/E/2014/01 1982 held by the National Autonomous University of Mexico [as registered in the National Institute for Industrial Protection (INPI), Mexico City], and characterized by a long-extended action for up to 8-10 days. ${ }^{22}$ This preparation is recommended at a dose of $20 \mathrm{mg} / \mathrm{kg}$, administered subcutaneously in the loose area of the neck and shoulder region, administering no more than $10 \mathrm{ml}$ per site. Group 2 (26 and 19 bulls classified as severity 2 and 3 respectively; $n=45)$ was treated with tulathromycin (Tul) (Draxxin ${ }^{\circledR}$, Zoetis, Mexico City, Mexico) at a dose of $2.5 \mathrm{mg} / \mathrm{kg}$, also injected subcutaneously in the body regions already mentioned, administering no more than $7.5 \mathrm{ml}$ per site. A single treatment was administered per bull in both groups.

Before the treatment, nose mucous samples were obtained from all bulls considered as having BRD. The animal's head was restrained by an assistant and the external nares were wiped clean of discharges. The sample was obtained by gently 
Table 1. Sample size and mean \pm 1SD values for weight and bovine respiratory disease classification of the steers enrolled in this trial.

\begin{tabular}{|c|c|c|c|c|c|c|}
\hline \multirow{2}{*}{ Treatment } & \multirow{2}{*}{$\square$} & \multirow{2}{*}{$\begin{array}{c}\text { Weight } \\
\text { (kg) }\end{array}$} & \multicolumn{4}{|c|}{ Respiratory disease classification } \\
\hline & & & 回 & 2 & 3 & $4 \square$ \\
\hline Tilmicosin-LA* & 44 & $241 \pm 69$ & $3(7 \%)$ & $22(50 \%)$ & $18(41 \%)$ & $1(2 \%)$ \\
\hline Tulatromicina\# & 50 & $241 \pm 62$ & $4(8 \%)$ & $26(52 \%)$ & $19(38 \%)$ & $1(2 \%)$ \\
\hline
\end{tabular}

* Manufactured by Casal's Internacional S.A. de C.V; Guadalajara, Mexico, under Patent MX/E/2014/01 1982 held by the National Autonomous University of Mexico.

\# Draxxin ${ }^{\circledR}$, Zoetis

$\square$ Not included in this trial

Table 2. Clinical assessment of steers to grade the severity of a bovine respiratory infection.

\begin{tabular}{|l|l|}
\hline \multicolumn{1}{|c|}{ Scale } & \multicolumn{1}{c}{ Description } \\
\hline 1 & Normal, alert and receptive \\
\hline 2 & $\begin{array}{l}\text { Mild depression, characterized by mild lethargy, noticeable weakness, mild } \\
\text { reduction in intestinal filling and / or lack of attention to the environment and } \\
\text { reduced willingness to move as a response to disturbances }\end{array}$ \\
\hline 3 & $\begin{array}{l}\text { Moderate to marked depression, characterized by lethargy, marked weakness, } \\
\text { reduction in intestinal filling and / or lack of attention to the environment and } \\
\text { unwillingness to move as a response to stimulus }\end{array}$ \\
\hline 4 & Moribund \\
\hline
\end{tabular}

rubbing a sterile polyester-tipped swab deeply and rotated firmly against the mucous of the bull's nostril walls according to a previous report. ${ }^{27}$ Subsequently, the swabs were introduced in Stuart's transport medium and were sent to the Department of Bacteriology at the National Autonomous University of Mexico (UNAM) to be processed using standard microbiological techniques to selectively isolate and identify Mannheimia hemolytica, Pasteurella multocida, Haemophilus somnu and Mycoplasma bovis based on selective media and morphology, following validated procedures. $^{28}$

A sick steer treated as described was considered cured if it did not present any of the following symptoms: fever, nasal discharge, cough, ocular discharge, postural changes like the position of the ears, opened front legs, stretched neck, refusing to move, or allowing to be trapped without opposing maneuvers, and the respiratory and heart rates were within ranges (35-40 breaths/min and $65-80$ beats/min, respectively). In addition, animals considered cured presented normal food intake and did not present flank depressions due to lack of food. 


\section{Statistics}

To estimate the potency of the trial, the sample size was incorporated post hoc to GPower $^{\circledR}$ analysis ${ }^{29}$ (Düseldorf, Germany). The minimum number of clinical cases affected by BRD per treatment group to achieve a power of 0.996 was 40 bulls. The endpoint of this study was a clinical cure or lack of it $(1,0)$, including mortality (registered as antibacterial failure), which was recorded on days 7, 15, and 30. Clinical resolution of the individual case was assumed when bulls lacked all clinical signs and could be graded as 1 according to Table 1. The clinical assessment of the bulls was carried out between 7 and 8 am and the inspection was repeated in the afternoon between 5 and 6 pm every day the trial lasted.

The clinical cure scores were analyzed using logistic regression and the goodness of fit model was proven according to the method proposed by Hosmer and Lemeshow. ${ }^{25}$ Goodness-of-fit tests helped to decide whether the model was correctly chosen. If it is below 0.05 , the model is rejected, and if it is higher, then it is approved. In the final model, only treatment (Til-group and Tul-group) was included. Homoscedasticity was assumed based on the likelihood of equal variances for both groups, considering the number of individuals included in the trial and the fact that they came from one single population. Analysis of arterial and venous parameters: $\mathrm{pH}_{1} \mathrm{pO}_{2}, \mathrm{pCO}_{2}, \mathrm{Na}^{+}, \mathrm{K}^{+}, \mathrm{Ca}^{2+}, \mathrm{Cl}^{-}, \mathrm{Lac}, \mathrm{Glu}, \mathrm{Ht} \%$, and temperature were carried out under the assumption that data were distributed in a normal manner and showed homoscedasticity. Therefore, a one-way ANOVA analysis, complemented by Tukey tests were performed. The differences at the level of $P<0.05$ were considered statistically significant. The statistical analysis was performed with SAS 9.3 statistical software (SAS Institute, 2009).

\section{Results and discussion}

A total of 94 bulls were included in the study. Although the same number of bulls was assigned to each group, the Til-group ended with 44 cases and Tul-group with 50 animals. The difference in number was due to the commercial policies imposed on the farm i.e., if a buyer requested some animals. In addition, two bulls were left out of the trial due to muscular and skin lesions that appeared after a bullfight. The proportions and characteristics of the animals included in the study are presented in Table 2. No mortality occurred in this trial. For the clinical cure rate on day 7 , a similar proportion of clinically cured cases were found for the Til-group (90.0\%; 36/40) and Tul-group (88.9\%; 40/45). Likewise, the success rate for the treatments was similar on days 15 and 30 (P>0.05) and all animals were regarded as healthy on days 15 and 30 for both treatment groups. In Table 3, the mean values and standard deviation of the blood chemistry variables are presented before and after either treatment. No statistically significant differences were found between the mean values of any variable assessed between groups ( $p>0.05$ in all cases). Also, no differences were found in body temperature either between clinical scores or between groups ( $p>0.05$ ), as shown in Figure 1. The total number of pathogens and their corresponding percentage value of isolates from the mucosal-nostril swab samples is presented in Table 4. Overall, the most common isolate was Mannhemia hemolytica 38.88\% (70/180), followed by Pasteurella 
Table 3. Mean \pm SD of the basic basal blood chemistry values of steers with respiratory disease and 15 days after a single injection of tilmicosin-LA* (20 mg / kg SC) or tulathromycin\# (2.5 mg / kg SC).

\begin{tabular}{|c|c|c|c|c|c|c|c|c|}
\hline \multirow[b]{3}{*}{ Parameter } & \multicolumn{4}{|c|}{ Thlmicosin-LA } & \multicolumn{4}{|c|}{ Tulathromycin } \\
\hline & \multicolumn{2}{|c|}{ Venous } & \multicolumn{2}{|c|}{ Arterial } & \multicolumn{2}{|c|}{ Venous } & \multicolumn{2}{|c|}{ Arterial } \\
\hline & Previous & 15 days later & Previous & $\begin{array}{l}15 \text { days } \\
\text { later }\end{array}$ & Previous & $\begin{array}{l}15 \text { days } \\
\text { later }\end{array}$ & Previous & $\begin{array}{l}15 \text { days } \\
\text { later }\end{array}$ \\
\hline $\mathrm{pH}$ & $7.49 \pm 0.07$ & $7.46 \pm 0.06$ & $7.55 \pm 0.08$ & $7.51 \pm 0.01$ & $7.48 \pm 0.03$ & $7.48 \pm 0.3$ & $7.6 \pm 0.05$ & $7.59 \pm 0.05$ \\
\hline $\mathrm{PCO}^{2}(\mathrm{mmHg})$ & $36 \pm 5.47$ & $39 \pm 8.65$ & $77 \pm 12.03$ & $66 \pm 20.38$ & $36 \pm 4.13$ & $41 \pm 3.44$ & $86 \pm 32.69$ & $86.66 \pm 15.50$ \\
\hline $\mathrm{PO}^{2}(\mathrm{mmHg})$ & $41 \pm 5.95$ & $38.90 \pm 5.40$ & $33.7 \pm 5.03$ & $40.1 \pm 3.60$ & $37.2 \pm 4.91$ & $39.70 \pm 5.16$ & $31.8 \pm 6.40$ & $32.30 \pm 1.40$ \\
\hline $\mathrm{Na}^{+}(\mathrm{mmol} / \mathrm{l})$ & $140 \pm 5.34$ & $140 \pm 2.54$ & $136 \pm 6.03$ & $138 \pm 4.01$ & $140.5 \pm 1.94$ & $137.50 \pm 2.60$ & $137.33 \pm 5.50$ & $136 \pm 2$ \\
\hline $\mathrm{K}^{+}(\mathrm{mmol} / \mathrm{l})$ & $4.50 \pm 0.38$ & $4.80 \pm 0.31$ & $4.3 \pm 0.02$ & $4 \pm 1.30$ & $4.8 \pm 0.34$ & $4.6 \pm 0.24$ & $4.16 \pm 0.30$ & $4.06 \pm 0.15$ \\
\hline $\mathrm{Ca}^{++}(\mathrm{mmol} / \mathrm{l})$ & $1.14 \pm 0.06$ & $1.23 \pm 0.07$ & $1.16 \pm 0.05$ & $1.08 \pm 0.08$ & $1.16 \pm 0.09$ & $1.18 \pm 0.04$ & $1.18 \pm 0.12$ & $1.13 \pm 0.13$ \\
\hline $\mathrm{CL}^{-}(\mathrm{mmol} / \mathrm{l})$ & $99 \pm 7.34$ & $100.50 \pm 3.39$ & $98 \pm 5.30$ & $98 \pm 6.70$ & $100.5 \pm 4$ & $98 \pm 3.01$ & $99 \pm 6$ & $99 \pm 1.41$ \\
\hline Glu (mg/dl) & $3.65 \pm 0.48$ & $3.40 \pm 0.56$ & $3.9 \pm 0.03$ & $3.7 \pm 0.03$ & $3.6 \pm 1.03$ & $3.4 \pm 0.28$ & $3.86 \pm 0.58$ & $3.83 \pm 0.58$ \\
\hline Lac (mg/dl) & $0.95 \pm 2.84$ & $1.87 \pm 1.91$ & - & - & $1.76 \pm 0.25$ & $0.9 \pm 0.88$ & $0.38 \pm 0.01$ & $0.44 \pm 0.07$ \\
\hline $\mathrm{Ht}(\%)$ & $26 \pm 3.79$ & $29 \pm 3.58$ & $25 \pm 4.65$ & $26 \pm 5.04$ & $25.5 \pm 2.48$ & $25.5 \pm 3.61$ & $24.66 \pm 4.93$ & $24 \pm 2.64$ \\
\hline
\end{tabular}

* Manufactured by Casal's Internacional S.A. de C.V; Guadalajara, Mexico, under Patent MX/E/2014/01 1982 held by the National Autonomous University of Mexico.

\# $\quad \operatorname{Draxxin}^{\circledR}$, Zoetis 


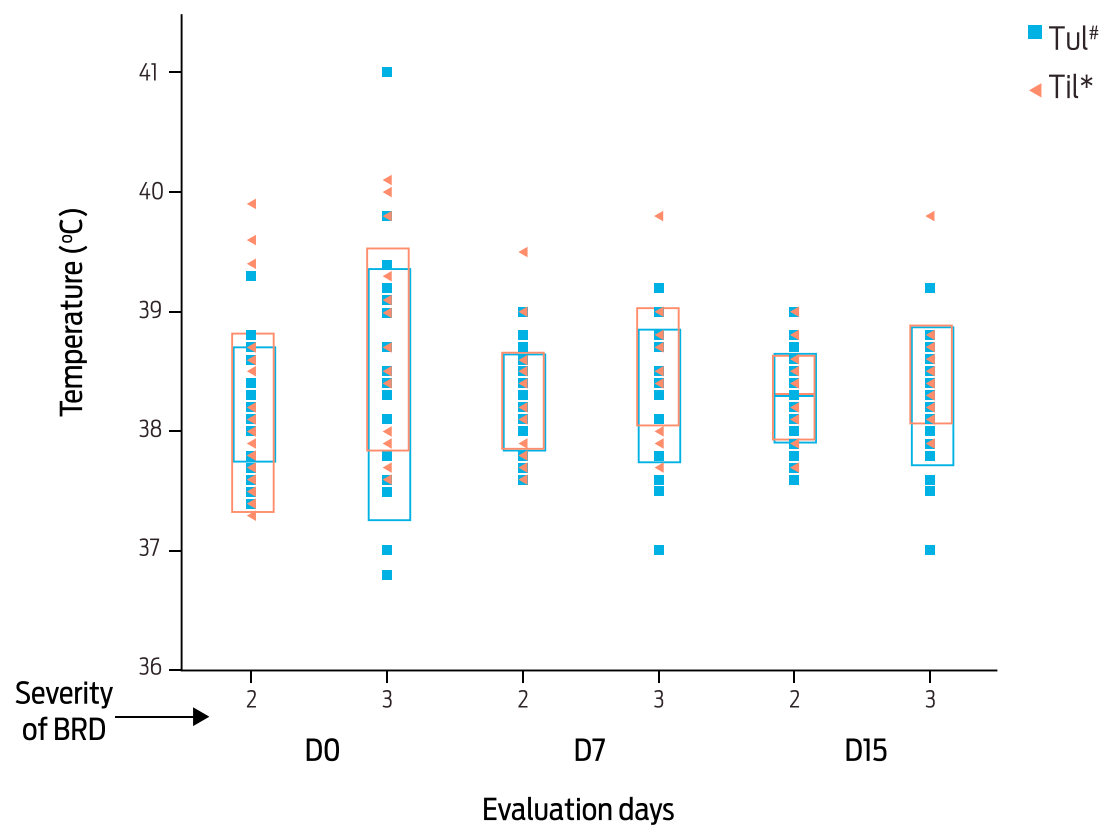

Figure 1. Individual data, means, and standard deviations (presented as boxes) of body temperature in steers with bovine respiratory disease (BRD), before and after a single injection of tulathromycin (red triangles)\# or tilmicosin-LA* (blue squares).

* Manufactured by Casal's Internacional S.A. de C.V; Guadalajara, Mexico, under Patent MX/E/2014/011982 held by the National Autonomous University of Mexico.

\# $\quad$ Draxxin ${ }^{\circledR}$, Zoetis.

Table 4. Microbiological findings from mucosa-nostril swabs obtained from 94 bulls affected of bovine respiratory disease and randomly divided into two groups to be treated as follows: 44 bulls treated with tilmicosin-LA* (group Til) $20 \mathrm{mg} / \mathrm{kg}$, and 50 bulls treated with tulathromycin\# (Tul) $2.5 \mathrm{mg} / \mathrm{kg}$.

\begin{tabular}{|c|c|c|c|c|c|}
\hline \multicolumn{7}{|c|}{$\%$ and (number) of isolates } \\
\hline Group & $\begin{array}{c}\text { Mannhemia } \\
\text { hemolytica }\end{array}$ & $\begin{array}{c}\text { Pasteurella } \\
\text { multocida }\end{array}$ & $\begin{array}{c}\text { Histophilus } \\
\text { Somni }\end{array}$ & $\begin{array}{c}\text { Trueperella } \\
\text { pyogenes }\end{array}$ & $\begin{array}{c}\text { Total } \\
\text { isolates }\end{array}$ \\
\hline Til & $37.36(34)$ & $27.47(25)$ & $19.78(18)$ & $15.38(14)$ & 91 \\
\hline Tul & $40.44(36)$ & $24.71(22)$ & $16.85(15)$ & $17.97(16)$ & 89 \\
\hline Per cent mean & 38.9 & 26.09 & 18.31 & 16.67 & 180 \\
\hline
\end{tabular}

* Manufactured by Casal's Internacional S.A. de C.V; Guadalajara, Mexico, under Patent MX/E/2014/01 1982 held by the National Autonomous University of Mexico.

\# Draxxin ${ }^{\circledR}$, Zoetis

$\S$ More than one bacterium was isolated in more than half of the nostrils swabs. 
multocida $26.11 \%$ (47/180), Histophilus somni 18.33\% (33/180), and Trueperella pyogenes $16.66 \%$ (30/180).

Although in many countries the metaphylactic antibiotic therapy has been linked to the emergence of resistant microorganisms, ${ }^{30-32}$ others have recommended that metaphylaxis should be implemented under certain beef-production circumstances, such as the ones described for the feedlot chosen in this trial. ${ }^{33}$ The timing of the antibiotic administration for the metaphylactic treatment may be set before the peak of clinical incidence of BRD, which has been suggested to occur approximately three weeks after the arrival of new bulls to the operation. ${ }^{2}$ However, the implementation of a metaphyilaxis is not always accepted as cost-effective by producers, as in the chosen feedlot for this study. In this trial, only BRD-affected bulls graded as severity 2 and 3, were detected and treated (Table 2). This shows poor health assessment based on the idea that early diagnosis should detect the majority of patients graded 2 when recovery is more feasible. Under these conditions, a comparative test was carried out for the treatment of outbreaks of BRD and with two of the preferred macrolide antibiotics, tulathromycin, and a novel preparation of sustained-release tilmicosin.

Metaphylaxis antibiotic therapy has been supported by some authors to deal with BRD. ${ }^{18-20}$ The use of macrolides such as tilmicosin and tulathromycin has been linked to a higher rate of enterococcal resistance to erythromycin. ${ }^{32}$ The Canadian Public Health Agency recommends that antibiotics should be used exclusively to actively treat infections and should not be used in a metaphylactic manner or as a long-term massive medication. ${ }^{34}$ Furthermore, the trend for the administration of antimicrobial drugs is being changed in Latin America towards treating active cases of BRD. In this context, several clinical studies have demonstrated the therapeutic efficacy of various antimicrobials for the treatment of BRD, including florfenicol, tilmicosin, tulathromycin, gamithromycin, ceftiofur- $\mathrm{Na}$, ceftiofur- $\mathrm{HCl}$, and ceftiofur crystalline free acid, as well as long-acting oxytetracycline. However, tulathromycin and the reference-tilmicosin (Micotil ${ }^{\circledR}$; Elanco Animal Health) stand out as the top antimicrobial drugs, as far as efficacy to treat BRD is concerned. ${ }^{35}$ Yet, the duration of plasma therapeutic concentrations is very different i.e., approximately 10 days vs. 2-3 days for tulathromycin and tilmicosin, respectively. ${ }^{36}$ It is worth pointing out that several studies have compared the treatment efficacy when using tulathromycin $(2.5 \mathrm{mg} / \mathrm{kg})$ or the standard pharmaceutical form of tilmicosin $(10 \mathrm{mg} /$ $\mathrm{kg}) .{ }^{35-37}$ They have shown that the relative risk of re-treatment was not different between these antibacterial drugs, but the cure rate of calves treated with tulathromycin tended to be significantly higher than that of calves treated with tilmicosin. In contrast, in this trial no difference in cure rate was observed for tilmicosin on days 7,15 , or 30 , reaching a $100 \%$ cure rate in both groups. One possible explanation for the lack of real differences in clinical cure in this study, as compared with reported results in the available literature, is that the novel pharmaceutical preparation of tilmicosin utilized, maintains therapeutic plasma concentrations for up to 8-10 days ${ }^{22}$ and theoretically, much higher concentrations in respiratory tissues. ${ }^{36,38} \mathrm{Ad}$ ditionally, the immunomodulatory and anti-inflammatory effects of tilmicosin could have contributed to the cure rate here observed, as it has been demonstrated that tilmicosin can both modulate the inflammatory process in respiratory tissue of cattle and restrain the pro-inflammatory effects of alveolar macrophages. ${ }^{39,40}$ These results are not entirely unpredictable since the clinical efficacy of the reference tilm- 
icosin (Micotil $\left.{ }^{\circledR}\right)$ for the treatment of BRD has been considered as very good 27,35 and such description comes from therapeutic plasma concentrations lasting only 48 to $72 \mathrm{~h},{ }^{36}$ while the tilmicosin preparation utilized in this trial lasted 8-10 days in plasma complying thus with outstanding PK/PD-ratios for a time-dependent antimicrobial drug. That is, with plasma concentrations that remain at or above the MIC value approximately three times longer than the reference tilmicosin. The clinical efficacy of tulathromycin here observed was comparable to the one described in other studies. ${ }^{735,41}$ In addition, this drug has been found to possess a remarkable distribution to respiratory tissues and accumulates in neutrophils and alveolar macrophages. ${ }^{42}$ In this trial, statistically undistinguishable efficacies were observed for both antibiotic drugs, even though tulathromycin exhibits higher MIC values when the $\mathrm{pH}$ of media is acidified, much as when a respiratory infection modifies the respiratory tract milieu. ${ }^{43}$

Bulls classified 1 or 4 were not eligible for this study because they were either healthy bulls (grade 1) or bulls that needed, besides the antibacterial drugs, supportive therapy. This latter consideration could have influenced the end efficacies observed. The small number of bulls either graded 1 or 4 that are presented in Table 2, allow a general appreciation of the health status of the farm. In this study, neither gasometrical values nor body temperature or any other blood variable measured showed a difference between tilmicosin and tulathromycin groups ( $p>$ 0.05). The initial aim for this study was to set groups according to their gasometrical variables and body temperature. Unexpectedly, it was found that these variables and blood chemistry parameters showed neither a defined pattern nor a significant change after treatment ( $p>0.05)$. Hence, group setting was made only based on the clinical scale previously described. ${ }^{7}$ Similarly, the measurement of body temperature did not prove to be a reliable variable in terms of relating this parameter with the degree of BRD severity or even the presence or absence of BRD. In other studies, in which Mannheimia haemolytica was the inoculated pathogen, it was reported that only during the day of inoculation body temperatures rose. ${ }^{44}$ Similarly, it was reported that body temperature in heifers infected with Mannheimia haemolytica was higher at 8 and $48 \mathrm{hr}$ post-infection and the nasal temperature rose to a maximum at 14 and $18 \mathrm{~h}$ post-infection. ${ }^{45}$ In contrast to what was found in this study with the natural presentation of BRD, in another study, Schaefer et al. ${ }^{46}$ report that the maximum orbital temperature had a positive predictive value of $86 \%$ and a negative predictive value of $100 \%$. However, as in this study, these authors report that body temperature does not seem to be a predictive value concerning the severity of the particular case.

Previous studies have attempted to associate lung damage in cattle with a variety of physiological and behavioral parameters, including gas values in blood. 21,24 In general, these attempts have met with variable and often limited success. One study reported that after the experimental induction of pneumonia with Mannheimia haemolytica, an increase in $\mathrm{PaO}_{2}$ was observed instead of the expected decrease in this variable and there was no general association between the extent of damage to the lungs and $\mathrm{PaO}_{2}$ values. ${ }^{24}$ In another study, contrary to the expected decline in $\mathrm{CO}_{2}$ and $\mathrm{N}_{2} \mathrm{O}$ values in expired air, authors found an increased with the number of treatments. ${ }^{47}$ In contrast, Šoltésová et al. ${ }^{48}$ found in calves with severe respiratory infections that died within $48 \mathrm{~h}$, marked hypoxemia and hypercapnia. In any case, it is possible to think that cattle with a respiratory 
infectious process, is bound to suffer deleterious changes in their respiratory proficiency. This must change blood gases and modify acid-base balance. ${ }^{49,50}$ However, inconsistencies found in the literature and in this study give very low predictive value to the determination of blood gases as an indication of respiratory dysfunction. Reinhold ${ }^{51}$ explains that shortly before the bovine's death, the compensatory mechanisms of the respiratory system such as hyperventilation and increased heart rate can improve oxygen uptake, in spite of respiratory impairment. Additionally, the natural capability of cattle to compensate with their behavior when affected by a $B R D$, because they are prey animals in the wild, should be investigated. ${ }^{52}$

Concerning the microbiological results achieved in this trial, bacterial isolations match with the usual pathogens described for BRD. In one study, ${ }_{1}^{8}$ authors determined that the most frequently isolated pathogen in affected cattle was Pasterurella multocida (35\%). More recently, it was reported that the most isolated pathogen was Mannhemia haemolytica with $45 \% .{ }^{10}$ In this study, Mannhemia haemolytica reached 38.88\% of the isolates. These discrepancies are not extreme and may be the result of local environmental conditions in each field outbreak and stand out the difficulties associated with reaching epidemiological conclusions with such information. Additionally, bacteria recovered from healthy animals can be very similar to the ones observed in BRD affected ones. ${ }^{28,41}$

\section{Conclusions}

Due to the similar efficacies to cure BRD affected cattle with either the long-acting tilmicosin preparation or the tulathromycin preparation and considering the high post hoc power of this test $(1-\beta=0.996)$, the results of this trial can be taken as an indication of therapeutic equivalence. Then, the cost-benefit ratios may become an important factor for the decision of choosing either antibacterial preparation. In addition, further studies assessing production variables after treatment, even up to the assessment of carcass yield, as well as the rate of bacterial resistance induced by either drug, are advised. 


\section{Acknowledgements}

Consejo Nacional de Ciencia y Tecnología (CONACyT) Problemas Nacionales 203 and PAPIIT- UNAM IT201116. The authors thank Casal's Internacional S.A. de C.V, for the donation of both pharmaceutical preparations in test.

\section{Conflicts of interest}

Authors have no conflict of interests. The National Autonomous University of Mexico (UNAM), owner of the patent, is opened to licensing the novel preparation of the long- acting tilmicosin in the trial.

\section{Author contributions}

Conceptualization: H.S., L.G.; formal analysis: G.T.P., H.S., L.G.; funding acquisition: H.S.; investigation: J.A.V., M.V.; methodology: G.T.P., H.S., L.G.; project administration: H.S., L.G.; writing-original draft: H.S., L.G., M.V., J.A.V., G.T.P.

\section{References}

1. Matthews KH Jr. Antimicrobial drug use and veterinary costs in U.S. Livestock Production. Electronic Report from the Economic Research Service. USDA, Agriculture Information Bulletin. 2001;766.

2. Pardon B, Hostens M, Duchateau L, Dewulf J, De Bleecker K, Deprez P. Impact of respiratory disease, diarrhea, otitis and arthritis on mortality and carcass traits in white veal calves. BMC Vet Res. 2013;9:79.

3. Griffin D, Chengappa MM, Kuszak J, McVey DS. Bacterial Pathogens of the Bovine Respiratory Disease Complex. Vet Clin Food Anim. 2010;26:381-94.

4. McGuirk SM. Disease management of dairy calves and heifers. Vet Clin North Am: Food Anim Prac. 2008;24:139-53.

5. Leruste $H$, Brscic M, Heutinck LFM, Visser EK, Wolthuis-Fillerup $M$, et al. The relationship between clinical signs of respiratory system disorders and lung lesions at slaughter in veal calves. Prev Vet Med. 2012;105:93-100.

6. Buczinski S, Forte G, Francoz D, Belanger AM. Comparison of thoracic auscultation, clinical score, and ultrasonography as indicators of bovine respiratory disease in preweaned dairy calves. J Vet Int Med. 2014;28:234-42.

7. White BJ, Renter DG. Bayesian estimation of the performance of using clinical observations and harvest lung lesions for diagnosing bovine respiratory disease in post-weaned beef calves. J Vet Diagnostic Invest 2009;21:446-53.

8. Allen JW, Viel L, Bateman KG, Shewen PE, Physick-Sheard P. The microbial-flora of the respiratory-tract in feedlot calves - associations between nasopharyngeal and bronchoalveolar lavage cultures. Can J Vet Res. 1991;55:341-6.

9. Berman J, Francoz D, Dubuc J, Buczinski S. A randomized clinical trial of a metaphylactic treatment with tildipirosin for bovine respiratory disease in veal calves. BMC Vet Res. 2017; 13:176.

10. Taylor JD, Holland BP, Step DL, Payton M E, Confer AW. Nasal isolation of Mannheimia haemolytica and Pasteurella multocida as predictors of respiratory disease in shipped calves. Res Vet Sci. 2015;99:41-5.

11. Schaefer AL, Cook NJ, Bench C, Chabot JB, Colyn J, Liu T, et al. The non-invasive and automated detection of bovine respiratory disease onset in receiver calves using infrared thermography. Res Vet Sci. 2012;93:928-35. 
12. Alsemgeest SPM, Kalsbeek HC, Wensing Th, Koemn JP, Van Ederen AM, Gruys E. Concentrations of serum Amyloid a (SAA) and haptoglobin (HP) as parameters of inflammatory diseases in cattle. Vet Quart 1994;16:21-3.

13. Theurer ME, Anderson DE, White BJ. Effect of Mannheimia haemolytica pneumonia on behavior and physiologic responses of calves during high ambient environmental temperatures. J Anim Sci. 2013;91:3917-3929.

14. Ellis J, Waldner Ch, Gow S, Jackson M. Relationship of the extent of pulmonary lesions to the partial pressure of oxygen and the lactate concentration in arterial blood in calves experimentally infected with bovine respiratory syncytial virus. Can J Vet Res. 2013;77:205-10.

15. Ball JJ, Kegley EB, Sarchet J, Powell JG. Comparison of treatment protocols for bovine respiratory disease in high-risk, newly received beef calves. Applied Animal Science 2019;35:278-83. https:// doi.org/10.15232/aas.2018-01836.

16. Abell KM, Theurer ME, Larson RL, White BJ, Apley M. A mixed treatment comparison meta-analysis of metaphylaxis treatments for bovine respiratory disease. J Anim Sci. 2017;95:626-35.

17. Poulsen-Nautrup B, Van Vlaenderen I, Decker M, Cleale RM. Antimicrobial drug use for control and treatment of bovine respiratory disease in U.S. feedlot cattle: A meta-analysis. Bov Pract. 2017;51:1-13.

18. Crosby $S$, Credille B, Giguère $S$, Berghaus R. Comparative efficacy of enrofloxacin to that of tulathromycin for the control of bovine respiratory disease and prevalence of antimicrobial resistance in Mannheimia Haemolytica in calves at high risk of developing bovine respiratory disease. J Anim Sci. 2018;96:125967. doi: 10.1093/jas/sky054.

19. Lathers CM. Role of Veterinary Medicine in Public Health: Antibiotic Use in Food Animals and Humans and the Effect on Evolution of Antibacterial Resistance. J Clin Pharmacol. 2001;41:595-9. doi: 10.1177/00912700122010474.

20. Palma E, Tilocca B, Roncada P. Antimicrobial resistance in veterinary medicine: An overview. Int J Mol Sci. 2020;21:1914. doi:10.3390/ijms2 1061914

21. Gunes V, Atalanm G. Comparison of ventral coccygeal arterial and jugular venous blood samples for $\mathrm{pH}, \mathrm{pCO} 2, \mathrm{HCO} 3, \mathrm{Be}$ (ecf) and ctCO 2 values in calves with pulmonary diseases. Res Vet Sci. 2006;81:148-51.

22. Gutiérrez L, Soriano R, Martínez-Cortes I, Miranda-Calderon J, Sumano H. Pharmacokinetics of a new parenteral formulation of Tilmicosin-La in cows. Pak Vet J. 2016;36:165-8.

23. Mendoza J, Martínez-Cortés I, López-Ordaz R, Gutiérrez L, Sumano, H. Concentrations of tilmicosin in mammary gland secretions of dairy cows following subcutaneous administration of one or two doses of an experimental preparation of tilmicosin and its efficacy against intramammary infections caused by Staphylococcus aureus. Am J Vet Res. 2016;77:922-30.

24. Hanzlicek GA, White BJ, Mosier D, Renter DG, Amderson DE. Serial evaluation of physiologic, pathological, and behavioral changes related to disease progression of experimentally induced Mannheimia haemolytica pneumonia in postweaned calves. Am J Vet Res. 2010;71:359-69.

25. Hosmer DW, Lemeshow S. Applied logistic regression, 2nd ed. Hoboken, NJ: Jonh Wiley \& Sons; 2000. p. 144-60. 
26. Godinho KS, Sarasola P, Renoult E, Tilt N, Keane S, Windsor GD, et al. Use of deep nasopharyngeal swabs as a predictive diagnostic method for natural respiratory infections in calves. Vet Rec. 2007;160:22-5.

27. Rishmawi N, Ghneim R, Kattan R, Ghneim R, Zoughbi M, Abu-Diab A, et al. Survival of fastidious and nonfastidious aerobic bacteria in three bacterial transport swab systems. J Clin Microb. 2007;4:1278-83.

28. Faul F, Erdfelder E, Lang AG, Buchner A. G*Power 3: A flexible statistical power analysis program for the social, behavioral, and biomedical sciences. Beha Res Meth. 2007;39:175-91.

29. CIPARS report, 2013. Available from: http://www.phac-aspc.gc.ca/cipars-picra/2013/annu-reportrapport-eng.php

30. Rerat $M$, Albini $S$, Jaquier $V$, Hussy D. Bovine respiratory disease: Efficacy of different prophylactic treatments in veal calves and antimicrobial resistance of isolated pasteurellaceae. Prev Vete Med. 2012;103:265-73.

31. Zaheer R, Cook SR, Klima CL, Stanford K, Alexander T, Topp E, et al. Effect of subtherapeutic vs. therapeutic administration of macrolides on antimicrobial resistance in Mannheimia haemolytica and enterococci isolated from beef cattle. Front Microbiol. 2013;4:133.

32. BCRC. Beef Cattle Research Council. Bovine Respiratory Disease. March, 2018, Available from: http://www.beefresearch.ca/research-topic.cfm/ bovine-respiratory-disease-38.

33. Doering R. Reducing antibiotics in meat. Food Law. 2014;22.

34. Aytekin I, Mamak N, Onmaz AC, Sakin F, Aslan S. Effects of Tulathromycin and Tilmicosin Application in the Treatment of Bovine Respiratory Disease in Cattle. Vet Fakultesi Dergisi. 2010;21:159-62.

35. Lombardi KR, Portillo T, Hassfurther R, Hunter RP. Pharmacokinetics of tilmicosin in beef cattle following intravenous and subcutaneous administration. J Vet Pharmacol Ther. 2011;34:583-7.

36. Skogerboe TL, Rooney KA, Nutsch RG, Weigel DJ, Gajewski K, Kilgore WR. Comparative efficacy of tulathromycin versus florfenicol and tilmicosin against undifferentiated bovine respiratory disease in feedlot cattle. Vet Ther. 2005;2:180-96.

37. Soliman AM, Ali-Ayad AR. Pharmacokinetics and efficacy of tilmicosin in the treatment of Pasteurella haemolytica bronchopneumonia in calves. Pharm Pharmacol. 2014;5:514-23.

38. Chin AC, Lee WD, Murrin KA, Morck DW, Merrill JK, Dick P, et al. Tilmicosin Induces Apoptosis in Bovine Peripheral Neutrophils in the Presence or in the Absence of Pasteurella haemolytica and Promotes Neutrophil Phagocytosis by Macrophages. Antim Agen Chemother. 2000;44:2465-70.

39. Fajt VR. The effects of danofloxacin and tilmicosin on peripheral neutrophils in healthy cattle, on peripheral neutrophils in cattle with induced Pasteurella haemolytica pneumonia, and on body temperature measured via radiotelemetry in cattle with induced Pasteurella haemolytica pneumonia. Retrospective Theses and Dissertations 13896. 2000. Available from: http://lib.dr.iastate.edu/ $\mathrm{rtd} / 13896$

40. Godinho KS, Rae A, Windsor GD, Tilt N, Rowan TG, Sunderland SJ. Efficacy of tulathromycin in the treatment of bovine respiratory disease associated with induced M. bovis infections in young dairy calves. Vet Theraphy. 2005;6:96-112. 
41. Nowakowski MA, Inskeep PB, Risk JE, Skogerboe TL, Benchaoui HA, Meinert TR, et al. Pharmacokinetics and lung tissue concentrations of tulathromycin, a new triamilide antibiotic, in cattle. Vet Ther. 2004;5:60-74.

42. Evans NA. Tulathromycin: an overview of a new triamilide antibiotic for livestock respiratory disease. Vet Ther. 2005;6:83-95.

43. Rose-Dye TK, Burciaga-Robles LO, Krehbiel CR. Rumen temperature change monitored with remote rumen temperature boluses after challenges with bovine viral diarrhea virus and Mannheimia haemolytica. J Anim Sci 2011;89:1193-2000.

44. Theurer ME, White BJ, Larson RL, Holstein KK, Amrine DE. Relationship between rectal temperature at first treatment for bovine respiratory disease complex in feedlot calves and the probability of not finishing the production cycle. J Am Vet Med Assoc. 2014;245:1279-85.

45. Schaefer AL, Cook NJ, Church JS, Basarab J, Perry B, Miller C, et al. The use of infrared thermography as an early indicator of bovine respiratory disease complex in calves. Res Vet Sci. 2007;83:376-84.

46. Burciaga-Robles LO, Holland BP, Step DL, Krehbiel CR, McMillen GL, Richards $\mathrm{CJ}$, et al. Evaluation of breath biomarkers and serum haptoglobin concentration for diagnosis of bovine respiratory disease in heifers newly arrived at a feedlot. Am J Vet Res. 2009;70:1291-8.

47. Šoltésová H, Nagy O, Tóthová C, Paulíková I, Seidel H. Blood gases, acid-base status and plasma lactate concentrations in calves with respiratory diseases. Acta Vet Beograd. 2015;65:111-24.

48. Collie DDS. Pulmonary function changes and clinical findings associated with chronic respiratory disease in calves. Brit Vet J. 1992;148:33-40.

49. Reinhold P, Födisch G. Lungen function diagnostik bei gesunden und and Pneumonieerkrankten Kälbern. Mh. Vet Med. 1993;48:113-7.

50. Reinhold P. Physiological and pathophysiological aspects of respiratory function in the bovine species. Tierärztl Umschau. 1997;52:584-92.

51. Weary DM, Huzzey JM, Von-Keyserlingk MA. Board-invited review: using behavior to predict and identify ill health in animals. J Anim Sci. 2009;87:770-7. 